\title{
Application of Requirements Engineering in the Development of a Universal Basic Platform of a Four-axle Locomotive \\ A.K. Friesen
}

Centre of innovative development Sinara Transport Machines LLC., Russia, 620014, Ekaterinburg, Marshala Zhukova street, 6

\section{Annotation}

The article presents the practice of using system methods in the development of a universal four-axle locomotive platform. The work is aimed at developing the optimal design of the frame and bodies of the locomotive, the choice of power and traction components to simplify the design process, reduce development time and reduce the cost of the product. The advantages of applying a systematic approach to working with requirements, determining the necessary functions and forming the structure of the product are described.

Corresponding Author:

A.K. Friesen

a.k.frizen@mail.ru

Received: 5 March 2020

Accepted: 18 March 2020

Published: 8 April 2020

Publishing services provided by

Knowledge E

(c) A.K. Friesen. This article is distributed under the terms of the Creative Commons

Attribution License, which permits unrestricted use and redistribution provided that the original author and source are credited.

Selection and Peer-review under the responsibility of the SEC 2019 Conference Committee.

\section{G OPEN ACCESS}

\section{Introduction}

In 2019, there was such a situation on the routes of non-public use of private enterprises that about 2000 industrial locomotives can be stopped and not allowed to operate because of their technical condition, which does not meet the requirements of the technical regulations of the Customs Union. According to the rules of technical operation, it is prescribed to extend the service life of locomotives only after their modernization and certification, which is comparable in cost to the purchase of new equipment [1]. Industrial enterprises are located on the vast territory of Russia with different climatic conditions and different enterprises have their own requirements for railway equipment, for example:

1) required power;

2) operating conditions;

3) the level of maintenance and repair;

4) intensity of use per day; 
Another important requirement of Industrialists is the reduced cost of the locomotive throughout the life cycle, which includes (for the consumer) the purchase price of equipment, maintenance costs: fuel consumption, maintenance and repair. Also pay attention to the modern working conditions of locomotive crews.

All this leads to the creation of different locomotives for specific customer conditions. The manufacturer of equipment in turn bears the following costs:

1) development of design, technological and repair documentation;

2) software development;

3) technological preparation of production;

4) prototype manufacture;

5) testing and certification of pilot product;

6) preparation of production for serial production of the product;

In such a situation, in order to maintain its position in the market, the manufacturer has to solve the difficult task of minimizing costs while maintaining the quality of products and meeting the maximum number of end users. In this regard, it was decided to develop a universal platform on the basis of which it is possible to build different locomotives relatively quickly and at low cost [2-3]. The concept of the future project was chosen as a modular design of locomotives with two engines from trucks of well-known and proven manufacturers. Due to the simple change of modules, it is possible not only to change the characteristics of products, but also to quickly bring it into working condition in case of possible equipment breakdowns, thereby eliminating downtime. For the basic elements already certified trucks of the commercially produced locomotive TEM9 are accepted, it remains to develop a unified frame and body for placing different equipment on/in them. The first locomotives built according to this concept WERE the TEMG1 and TEM10 shunting locomotives, they have different types of engines (gas piston and diesel), different safety systems. TEM10 can be equipped with diesel engines of three different brands, as well as has the potential to create a hybrid and all-electric versions. There are a number of optional systems, relative to the basic versions, for more affluent consumers. This was achieved through the application of system engineering practices, namely requirements engineering, construction of functional and structural schemes of the product. 


\section{Results and Discussions}

The first stage of the work is to work with the requirements. For this purpose the reverse engineering method is applied. We consider locomotives as "black boxes" [4] and make a separate list of requirements for each locomotive. Requirements are taken from the product specifications and standards specified in the job. They include requirements for functionality, design, layout, individual units and systems. In view of the fact that often not all requirements for development are taken into account in technical specifications and there are vague and not exact formulations, the search is conducted for undisclosed hidden requirements. In parallel with this process, a request is made to the certification body to provide a list of certification requirements for such locomotives, in order to once again verify the correctness of the basic requirements. The next step is to add the constraints of the selected production site to both lists. As a result, we get two lists of requirements and restrictions, analyze them and come to the conclusion that most of the requirements are the same.

When you impose stakeholder requirements on a system, you can work with it as a "transparent box" [4]. At this stage, the product architecture appears: the system functions are described, the functional structures are compiled, the component base is specified, the function-design scheme is built, the overall structure of the product is compiled and decomposed to small nodes. After drawing up the function - design scheme, it became clear which nodes will differ in the locomotives, and which will become common. Different elements were allocated in the structure into separate nodes, so that it was possible to quickly and without consequences for the basic elements to carry out changes in the future. For example, the side platforms in the locomotive frame were removed from the frame to the upper level, in the frame Assembly. This and other solutions allowed the locomotive frame to remain the basic unchanged platform for both locomotives. In the bodies and units used, similar decisions were also made: the body designs remain unchanged for both locomotives, only the welded parts needed to install different engines are changed, the traction unit is used alone. The layout solution allowed to borrow 4 modules from 7 without changes.

\section{Acknowledgement}

This article describes the practice of using systemic methods in developing a universal four-axle locomotive platform. Using detailed work with requirements and drawing up a detailed architecture of the product, a mock-up solution was created in which 3 modules 
were changed, which made it possible to develop a single platform for two locomotives. In practice, this would make it possible to ensure a high degree of unification, increase the tactfulness of production, reduce the time for designing products and reduce the cost of design and technological training in the production of new types of equipment.

\section{References}

[1] Guide to the Systems Engineering Body of Knowledge (SEBoK).

[2] OECD Science, Technology and Industry Scoreboard 2015: Innovation for growth and society [Electronic resource] / OECD Publishing. - Paris, 2015. - 264 p. - Mode of access: http://dx.doi.org/10.1787/sti_scoreboard-2015-en.

[3] System thinking: Textbook / Anatoly Levenchuk.-Boston-Country-Kiev: The Project "Self-Indulgence", Toliman, 2019.- 534p.

[4] Proceedings of the 7th International CDIO Conference, Technical University of Denmark, Copenhagen, June 20 - 23, 2011. 42 p. - Mode of access: http: //publications.lib.chalmers.se/records/fulltext/local_143186.pdf. 